\title{
No evidence of caries reduction found in a school xylitol and erythritol lozenge programme
}

\author{
Abstracted from \\ Lenkkeri A-M, Pienihäkkinen K, Hurme S, Alanen P. \\ The caries-preventive effect of xylitol/maltitol and erythritol/maltitol lozenges: \\ results of a double-blinded, cluster-randomized clinical trial in an area of natural fluoridation. \\ Int J Paediatr Dent 2011 Sep 23. doi:10.1111/j.1365-263X.2011.01182.x. [Epub ahead of print] \\ Address for correspondence: AM Hietala-Lenkkeri. Carea Joint Municipal Authority for \\ Medical and Social Science in Kymenlaakso, Kuusankoski, Finland. E-mail: aija.hietala-lenkkeri@fimnet.fi
}

\section{Question: Is a one yearly or two yearly school programme using xylitol or erythritol lozenges, as an adjunct to a comprehensive oral health improvement programme effective at reducing dental caries in school children?}

Design A double-blind, cluster-randomised, double-blinded clinical trial was conducted.

Intervention All children within a fluoridated area with low caries received oral health programmes based on their estimated risk of caries. The children were divided into five groups. Four groups received three times daily xylitol/maltitol $(4.7 \mathrm{~g} / 4.6 \mathrm{~g})$ lozenges or erythritol/maltitol $(4.5 \mathrm{~g} / 4.2 \mathrm{~g})$ lozenges for either one or two school years. One group did not receive lozenges. Clinical examination was undertaken at baseline and after 48 months primarily by one dentist who was blinded to the assignment of each child. Radiographical examination was undertaken at 48 months, with two calibrated dentists undertaking the analysis. Outcome measure Change in caries: decayed missing or filled surfaces at dentinal level ( $\triangle \mathrm{D} 3 \mathrm{MFS})$.

Results Forty-eight months after commencement of the research there were no statistically significant differences between the proportion of $\triangle \mathrm{D} 3 \mathrm{MFS}=0$ (clinically or radiographically) within the groups (xylitol/ maltitol or erythritol/maltitol lozenges). Seventy-five of the children were lost to follow up, seven discontinued through other reasons. Conclusions The use of xylitol-maltitol or erythritol-maltitol lozenges within a cohort of low caries children either over nine months or 21 months were not effective in reducing dental caries in primary school children.

\section{Commentary}

Within this paper Hietala-Lenkkeri investigates a clearly focused question; whether the use of erythritol-maltitol (EM) and xylitolmaltitol (XM) lozenges, in addition to a comprehensive prevention programme could reduce dental decay in a low caries population of 10 year old children compared with a control group who received comprehensive treatment alone.

The use of xylitol lozenges has been researched in high caries populations, ${ }^{1-3}$ but not within low caries populations. Research on the cariogenic properties of erythritol is limited. ${ }^{4}$

This paper is of value both to clinicians and public health leaders as it investigates the actual caries preventative properties of both xylitol and erythritol in a school population.

Both the power calculation and the randomisation within this paper were clearly described, with children randomised to individual treatment clusters of similar size. The reader is not however advised how the randomisation took place eg using a sequence of random numbers from a statistical textbook, or a computer-generated sequence. ${ }^{5}$ Pragmatically, randomisation of classes rather than individuals is required within an oral health improvement project such as this, as it would be difficult to assign different lozenges at different time periods to individual children within classes.

It is noted that radiographs were not taken at the commencement of the study. Such a practice could be argued to be the most ethical to reduce radiation exposure to children. However calculating a combined radiographical and clinical $\triangle \mathrm{D} 3 \mathrm{MFS}$ is difficult without baseline radiographical information.

The DMFS index used here does not differentiate between early and late stage lesions. Newer caries assessment indices such as the ICDAS (International Caries Diagnosis and Assessment System http://www.icdas.org/) may be useful in future research to improve the sensitivity of caries diagnosis.

The number of children remaining in the study (496) is commendable, especially given the length of time of the study (up to 21 months). A flow diagram is presented allowing the reader to follow easily the progress of each cluster within the trial. Mathematical rigour is however important. To be pedantic, within this flow diagram there is one child (within the control group) that is not accounted for.

An intention to treat analysis should include a cumulative total of both groups so the reader can identify any change in mean caries within each group, across all the participants (whether they finished the trial or not). However this was not possible within this study as the children who dropped out were unable to be examined. 
Within the 24 month period there was a three month interlude where lozenges were not consumed, coincident with the time between the school years. It is possible that the summer break influenced the efficacy of the lozenges, although such a break has previously shown not to impact negatively on the long term efficacy of xylitol. ${ }^{6}$

Regular questionnaires regarding consumption of the product were not distributed to the children during the course of the trial, but were sent out after the trial was completed. Such regular collection of product consumption is important to reduce recall bias. Collecting unused product is also useful to verify consumption rates.

Within this study blinding was appropriate, with participating children (and parents), examining dentists, health care staff, chief investigator, teachers and the statistician all blinded until the data analysis had been completed.

All the groups were treated equally.

The majority of the children received a clinical examination from one clinician. It may have been useful for this examining dentist to have received some sort of external validation, to ensure intrarater reliability. For the minority of individuals who were examined by additional clinicians, external validation or periodic duplicate examinations would have also been appropriate for the reader to assess reliability and consistency. ${ }^{7}$ In contrast over 74 pairs of radiographs were examined by two dentists under optimal conditions, with an impressive $92.9 \%$ inter-examiner agreement.

The author used a probe to investigate the base of a lesion, which had 'to be soft instead of giving only a catch to the explorer'
Although there is no indication this would cause bias, and the use of a probe as part of a visuo-tactile clinical method is widespread, many regard that it is unethical to use an explorer in this way. ${ }^{8}$

Results were presented as control groups compared with XM (one year), XM (two years), EM (one year) and EM (two years). No data on the comparison (with statistical significance) between XM1 and XM2 or EM1 and EM2 were published, and this would have been helpful.

Brett G Duane

Department of Public Health, NHS Fife, Cameron Hospital, Windygates, Fife, UK

1. Alanen $\mathrm{P}$, Isokangas $\mathrm{P}$, Gutmann K. Xylitol candies in caries prevention: results of a field study in Estonian children. Community Dent Oral Epidemiol 2000; 28: 218-224.

2. Makinen KK, Pemberton D, Makinen PL, et al. Polyol-combinant saliva stimulants and oral health in Veterans Affairs patients--an exploratory study. Spec Care Dentist 1996; 16: 104-185.

3. Honkala E, Honkala S, Shyama M, Al-Mutawa SA. Field trial on caries prevention with xylitol candies among disabled school students. Caries Res 2006; 40: 508-513.

4. Makinen KK, Isotupa KP, Kivilompolo T, Makinen PL, Toivanen J, Soderling E. Comparison of erythritol and xylitol saliva stimulants in the control of dental plaque and mutans streptococci. Caries Res 2001; 35: 129-135.

5. Beller EM, Gebski V, Keech AC .Randomisation in clinical trials. Med J Aust 2002; 177: $565-567$.

6. Alanen $\mathrm{P}$, Isokangas $\mathrm{P}, \mathrm{Gutmann} \mathrm{K}$. Xylitol candies in caries prevention: results of a field study in Estonian children. Community Dent Oral Epidemiol 2000; 28: 218-224.

7. Davies GN, Cadell PB. Four investigations to determine the reliability of cariesrecording methods Arch Oral Biol 1963; 8: 331-348.

8. Pitts NB. Clinical Diagnosis of Dental Caries: A Perspective. Available at: http:// www.nidcr.nih.gov/NR/rdonlyres/F342B7B2-C1C9-4C05-9CE2-00A557E4E39A/0/ Nigel_Pitts.pdf

Evidence-Based Dentistry (2011) 12, 102-103. doi:10.1038/sj.ebd.6400822 